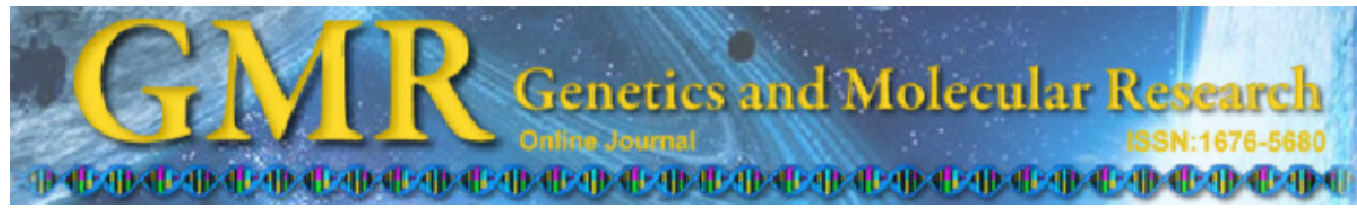

\title{
Esterase polymorphisms for analysis of genetic diversity and structure of soybean (Glycine max) cultivars
}

\author{
L.C. Valentini, C.A. Mangolin, S.A.O. Collet and M.F.P.S. Machado \\ Departamento de Biologia Celular e Genética da Universidade Estadual de \\ Maringá, Maringá, PR, Brasil
}

Corresponding author: M.F.P.S. Machado

E-mail: mfpsmachado@uem.br

Genet. Mol. Res. 10 (4): 2472-2481 (2011)

Received September 8, 2010

Accepted April 20, 2011

Published October 13, 2011

DOI http://dx.doi.org/10.4238/2011.October.13.4

\begin{abstract}
We used native polyacrylamide gel electrophoresis to identify polymorphism levels in $\alpha$ - and $\beta$-esterase loci from leaf tissues of Brazilian soybean cultivars for the analysis of population genetic diversity and structure, and to investigate relationships between conventional and genetically modified cultivars. The cultivars included lines developed by a soybean-grower cooperative (CD), by EMBRAPA (BR), and "Roundup Ready" (RR) cultivars. Esterase isozymes recorded with $\alpha$-naphthyl acetate and $\beta$-naphthyl acetate were produced from 14 loci. Two to three allelic variants were detected in leaves from 420 plants of $21 \mathrm{CD}, \mathrm{BR}$, and RR cultivars at Est-1, Est-2, Est-3, Est-5, and Est-14 loci. The estimated proportion of polymorphic loci in CD cultivars was $21.4 \%$, and in BR and RR cultivars it was $28.6 \%$. High and low $H_{\mathrm{O}}$ and $H_{\mathrm{E}}$ values were observed within $\mathrm{CD}$ and BR cultivars and a very high cultivar differentiation level was evident in the plants of the $21 \mathrm{CD}, \mathrm{BR}$, and RR cultivars $\left(F_{\mathrm{ST}}=0.3865\right)$. A low level of differentiation $\left(F_{\mathrm{ST}}=0.0289\right)$ was detected between conventional and RR cultivars. Plants from cultivar BR37 had the highest level of genetic differentiation compared to the other cultivars. The genetic basis of BR cultivars $(0.5538-0.9748)$ was found to be broader than the genetic
\end{abstract}


basis of CD cultivars $(0.7058$ for CD205 and CD209 and 0.9995 for CD205 and CD208). Higher genetic identity was detected between plants of CD and CDRR cultivars $(I=0.9816)$. Understanding the genetic structure of these populations can help provide specific culture strategies for each cultivar, depending on its level of heterozygosity.

Key words: Soybean; Esterase polymorphism; Genetic diversity

\section{INTRODUCTION}

Protein or enzyme electrophoresis is still the simplest tool to analyze a population's genetic structure in order to detect allele fixation and reproductively isolated and genetically divergent populations (Allendorf and Luikart, 2007). For example, esterase isozyme polymorphism (EC 3.1.1._) has been documented in plants since the 1960s (Schwartz, 1967); their specificity for different substrates allows simultaneous analysis of various loci in studies on genetic variations in plant populations. They are adequate co-dominant markers for the analysis of genetic structure in populations. Esterases are often found in multigene families (Oakeshott et al., 1993; Robin et al., 1996); 14 to 16 esterase isozymes have been detected by polyacrylamide gel electrophoresis (PAGE) in different plant species (Pereira et al., 2001; Carvalho et al., 2003; Orasmo et al., 2007; Frigo et al., 2009). A large number of esterase loci can be used simultaneously for the identification of genetic variation and for polymorphism analyses.

The PAGE system has been used for analysis of genetic diversity in peroba trees (Aspidosperma polyneuron; Carvalho et al., 2003), cassava (Manihot esculenta; Pereira et al., 2001), grapes (Vitis vinifera; Orasmo et al., 2007), and wild poinsettia (Euphorbia heterophylla; Frigo et al., 2009), but no such studies have been made of soybean (Glycine max) cultivars. Genetic diversity in soybean has been assessed using morphological traits (Perry et al., 1991), pedigrees (Zhou et al., 2000), geographic origins (Gorman, 1984), parentage coefficient (Miranda et al., 2007), isozymes (Yu and Kiang, 1993; Griffin and Palmer, 1995; Hirata et al., 1999), and DNA markers (Abdelnoor et al., 1995; Li and Nelson, 2001; Ude et al., 2003; Xu and Gai, 2003; Priolli et al., 2002, 2004; Bonato et al., 2006; Yamanaka et al., 2007; Fu et al., 2007; Hwang et al., 2008). An overview of genetic diversity in Chinese (Li et al., 2008; Wang et al., 2008), Japanese (Hwang et al., 2008), and Korean (Yoon et al., 2009) soybeans has been made using DNA markers.

Brazilian soybean cultivars have also been genetically characterized, mainly with parentage coefficient and DNA markers (Priolli et al., 2002, 2004; Bonato et al., 2006; Miranda et al., 2007). Brazilian agriculture uses a large number of improved cultivars adapted to the very diverse producing regions in Brazil. Brazil is the second largest soybean producer in the world, with a cultivated area of 24.7-25.0 million hectares, and a prevision of 72.2-73.3 million tons produced in the 2011/2012 season (http://www.conab.gov.br).

Development of new conventional and transgenic cultivars of soybean by breeding programs requires genetic markers for analysis of genetic polymorphism. Esterase polymorphism in the PAGE system has potential as a biochemical marker for the genetic characterization of soybean cultivars. The PAGE system may be used to estimate the propor- 
tion of polymorphic loci, number of alleles, proportion of alleles per polymorphic locus, frequency of alleles at each esterase locus, effective number of alleles, mean observed and expected heterozygosity, and to determine genetic differentiation within and among different soybean cultivars. Similarity among cultivars can also be determined. We used native PAGE to identify polymorphism in $\alpha$ - and $\beta$-esterase loci in leaf tissues of different soybean cultivars for analysis of genetic diversity and structure of populations, and to examine relationships between conventional and genetically modified cultivars.

\section{MATERIAL AND METHODS}

Seeds of the soybean cultivars CD and BR were obtained from COODETEC (Cooperativa Central de Pesquisa Agrícola) and EMBRAPA (Empresa Brasileira de Pesquisa Agropecuária), respectively. The seeds were superficially sterilized with $15 \%$ sodium hypochloride for $10 \mathrm{~min}$, and after extensive washing (4-5 times) with sterile water under aseptic conditions the seeds were distributed for germination on germtest paper. Germination occurred in a growth chamber at $25 \pm 2^{\circ} \mathrm{C}$ under $14.9 \mu \mathrm{mol} \cdot \mathrm{m}^{-2} \cdot \mathrm{s}^{-1}$ light radiation, provided by cold-white fluorescent lights, on a 12-h light-dark cycle for $120 \mathrm{~h}$. The plantlets obtained from germinated seeds were maintained at room temperature in a hydroponic system for 10 days, and leaves of each cultivar were used for the electrophoresis analysis.

The samples consisting of leaves collected from 20 plants of CD201, CD202, CD204, CD205, CD206, CD208, CD209, CD215, CD216, BR37, BR48, BRS133, BRS137, BRS184, BRS230, CD212RR, CD213RR, CD214RR, CD219RR, BR244RR, and AntaRR cultivars were evaluated by electrophoresis. Leaf pieces $(50 \mathrm{mg})$ were separately homogenized with a glass rod in a microcentrifuge tube using $50 \mu \mathrm{L}$ extraction solution prepared with $1.0 \mathrm{M}$ phosphate buffer, pH $7.0(890 \mu \mathrm{L})$, containing 5\% PVP-40 (50 mg), $1.0 \mathrm{mM}$ EDTA $(10 \mu \mathrm{L}), 0.5 \% \beta$-mercaptoethanol $(5 \mu \mathrm{L})$, and $10 \%$ glycerol solution $(50 \mu \mathrm{L})$ and maintained in an ice bath. After homogenization, the samples were centrifuged at 25,000 $\operatorname{rpm}(48,200 \mathrm{~g})$ for $30 \mathrm{~min}$, at $4^{\circ} \mathrm{C}$, in a Sorval $3 \mathrm{~K}-30$ centrifuge and the supernatant $(45$ $\mu \mathrm{L})$ was used from each sample.

Polyacrylamide gels (12\%) were prepared with $0.375 \mathrm{M}$ Tris- $\mathrm{HCl}, \mathrm{pH} 8.8$, as buffer (Ceron et al., 1992), $6.2 \mathrm{~mL}$ acrylamide/bis-acrylamide solution (30 g acrylamide and $0.8 \mathrm{~g}$ bis-acrylamide dissolved in $100 \mathrm{~mL}$ twice-distillated water), $4.0 \mathrm{~mL} 1.5 \mathrm{M}$ Tris- $\mathrm{HCl}$, $\mathrm{pH}$ 8.0, $6.2 \mathrm{~mL}$ twice-distilled water, $320 \mu \mathrm{L} 2 \%$ ammonium persulfate, and $16 \mu \mathrm{L}$ TEMED was used to separate the gel. The stack gel was prepared with $3.0 \mathrm{~mL}$ acrylamide/bisacrylamide $(5 \mathrm{~g}$ acrylamide and $0.25 \mathrm{~g}$ bis-acrylamide dissolved in $50 \mathrm{~mL}$ twice-distilled water), $3.0 \mathrm{~mL} 0.24 \mathrm{M}$ Tris-HCl, $\mathrm{pH}$ 6.8, $30 \mu \mathrm{L}$ twice-distilled water, $250 \mu \mathrm{L}$ ammonium persulfate $(2 \%)$, and $3 \mu \mathrm{L}$ TEMED. Electrophoresis was performed for $10 \mathrm{~h}$, at $4{ }^{\circ} \mathrm{C}$, at a constant voltage of $200 \mathrm{~V}$ (Pereira et al., 2001). Running buffer was $0.125 \mathrm{M}$ Tris/0.0959 M glycine, $\mathrm{pH}$ 8.3.

Esterases were identified by staining techniques described in Pereira et al. (2001). Gels were soaked for $30 \mathrm{~min}$ in $50 \mathrm{~mL} 0.1 \mathrm{M}$ sodium phosphate, $\mathrm{pH} \mathrm{6.2,} \mathrm{at} \mathrm{room} \mathrm{tempera-}$ ture. Esterase activity was visualized by placing the gels for $1 \mathrm{~h}$ in a staining solution prepared with $50 \mathrm{~mL}$ sodium phosphate solution, $30 \mathrm{mg} \beta$-naphthyl acetate, $40 \mathrm{mg} \alpha$-naphthyl acetate, $60 \mathrm{mg}$ Fast Blue RR salt, and $5 \mathrm{~mL} \mathrm{~N}$-propanol. For identify the $\alpha$ - and $\beta$-esterases, the gels were separately incubated with: i) $40 \mathrm{mg} \alpha$-naphthyl acetate; ii) $40 \mathrm{mg} \beta$-naphthyl 
acetate; iii) $40 \mathrm{mg} \alpha$-naphthyl and $30 \mathrm{mg} \beta$-naphthyl acetate; iv) $30 \mathrm{mg} \alpha$-naphthyl acetate and $40 \mathrm{mg} \beta$-naphthyl acetate. The esterases of the different bands have characteristic colors: $\alpha$ (black), $\beta$ (red), and $\alpha \beta$ (a mixture of black and red); these hydrolyze, respectively, $\alpha$-naphthyl acetate, $\beta$-naphthyl acetate, and both $\alpha$ - and $\beta$-naphthyl acetate.

Polyacrylamide gels, dried as described by Ceron et al. (1992), were kept at room temperature for $1 \mathrm{~h}$ in a mixture of $7.5 \%$ acetic acid and $10 \%$ glycerol embedded in 5\% gelatin. They were further placed between two sheets of wet cellophane paper stretched on an embroidering hoop and left to dry for 24-48 $\mathrm{h}$.

Genetic variability in the CD, BR, and RR (Roundup Ready) cultivars was analyzed with the POPGENE 1.32 Computer Program (Yeh et al., 1999) for the analysis of allele frequencies, observed and expected mean heterozygosity $\left(H_{\mathrm{O}}\right.$ and $\left.H_{\mathrm{E}}\right)$ and mean number of alleles per locus $\left(N_{\mathrm{A}}\right)$, mean number of alleles per polymorphic locus $\left(N_{\mathrm{A} \text { P }}\right)$, percentage polymorphic loci $(\% \mathrm{P}), \chi^{2}$ test for deviation from Hardy-Weinberg equilibrium, fixation index $\left(F_{\text {IS }}\right)$, genetic similarity or distance coefficients, and Wright's (1965) $F$-statistic values $\left(F_{\text {IT }}\right.$ and $\left.F_{\text {ST }}\right)$ for the CD and BR cultivars. Genetic identity (Nei, 1978) and distances among cultivars were calculated by UPGMA grouping.

\section{RESULTS}

Native PAGE analysis for esterase isozymes in leaves of the soybean cultivar plants, showed $\alpha$-preferential esterases (preferentially hydrolyzed $\alpha$-naphthyl acetate in the presence of $\alpha$ - and $\beta$-naphthyl acetate) and $\alpha / \beta$-esterases (equally hydrolyzed $\alpha$ - and $\beta$-naphthyl acetate) produced from 14 loci. The $\alpha$ - and $\alpha / \beta$-esterases were numbered in sequence, starting from the anode, according to decreasing negative charge (Figure 1). The characteristic band colors for the esterase isozymes correspond to the hydrolysis of either $\alpha$-naphthyl acetate (black) or both (a mixture of black and red). Esterases produced from Est-1, Est-10, Est-11, Est-12, and Est-13 loci hydrolyzed preferentially $\alpha$-naphthyl acetate ( $\alpha$-esterase; black bands), and esterases produced from Est-2, Est-3, Est-4, Est-5, Est-6, Est-7, Est-8, Est-9, and Est-14 loci utilized the $\alpha$ - and $\beta$-naphthyl acetates $(\alpha / \beta$-esterase) to the same extent (bands showing a mixture of black and red).

Two to three allelic variants were detected in leaves of the $21 \mathrm{CD}, \mathrm{BR}$, and RR cultivars at Est-1, Est-2, Est-3, Est-5, and Est-14 loci in 420 plants analyzed. Allele frequencies were analyzed for Est-1, Est-2, Est-3, Est-5, and Est-14 loci and estimated proportion of polymorphic loci $(\% \mathrm{P})$ in $\mathrm{CD}$ cultivars is $21.4 \%$ and in $\mathrm{BR}$ and RR cultivars is $28.6 \%$.

Table 1 shows the number of polymorphic loci $\left(N_{\mathrm{PL}}\right), \% \mathrm{P}, N_{\mathrm{A}}, N_{\mathrm{A} / \mathrm{PL}}$, effective number of alleles $\left(N_{\mathrm{E}}\right), H_{\mathrm{O}}$ and $H_{\mathrm{E}}$ in each of the cultivars. The estimated values in $\mathrm{BR}$ cultivars were higher than those detected in $\mathrm{CD}$ and RR cultivars. Whereas in the BR37 cultivar the highest $H_{\mathrm{O}}$ and $H_{\mathrm{E}}$ values were 0.27 and 0.29 , respectively, a lower value was recorded in BRS184 $\left(H_{\mathrm{O}}=0.02\right)$ and BRS230 $\left(H_{\mathrm{O}}=0.06\right)$. In the CD cultivars, the highest $H_{\mathrm{O}}$ value was 0.20 in the CD216 plants, and the lowest $(0.00)$ was recorded in CD215 plants. In the RR cultivars the highest $H_{\mathrm{O}}$ and $H_{\mathrm{E}}$ values were 0.22 and 0.2705 , respectively, in the CD212RR cultivar, and the lowest value was recorded in the CD214RR cultivar $\left(H_{\mathrm{O}}=0.00\right.$ and $\left.H_{\mathrm{E}}=0.1330\right)$.

Departure from Hardy-Weinberg equilibrium was observed in 14 of the 45 tests done 
on CD cultivars, in 12 of the 30 tests done in BR and RR cultivars (results not shown), resulting from a deficit in heterozygous plants. The $F_{\text {IS }}$ value was negative only in both CD206 ( $F_{\text {IS }}$ $=-0.1715)$ and BRS133 $\left(F_{\text {IS }}=-0.2121\right)$ cultivars (Table 1$)$, showing an excess of heterozygous plants. Since $H_{\mathrm{O}}$ was higher than $H_{\mathrm{E}}$ only in CD206 and BRS133 cultivars, excess homozygous plants (or deficit of heterozygous plants) occurred in the soybean cultivars.

A very high cultivar differentiation level $\left(F_{\mathrm{ST}}>0.25\right.$; Wright, 1978) was evident in the plants of the $21 \mathrm{CD}, \mathrm{BR}$, and RR cultivars $\left(F_{\mathrm{ST}}=0.3865\right.$; Table 2$)$. Accordingly, estimates of gene flow calculated from $F_{\text {ST }}$ were below the $N_{\mathrm{m}}=1$ level (Table 2). In contrast, a relatively low level of differentiation $\left(F_{\mathrm{ST}}<0.05\right)$ was detected between $\mathrm{CD}$ and BR cultivars $\left(F_{\mathrm{ST}}=0.017\right)$ and between $\mathrm{CD}$ and CDRR cultivars $\left(F_{\mathrm{ST}}=0.0261\right)$, which suggested a common genetic basis of founder soybean genotypes in the different breeding programs. The common genetic origin of soybean genotypes introduced in Brazil may be the reason for the low level of population differentiation in $\mathrm{CD}$ and BR plants. A low level of differentiation $\left(F_{\mathrm{ST}}=0.0289\right)$ was also detected between conventional cultivars $(9 \mathrm{CD}$ and 6 BR) and RR cultivars (CD212RR, CD213RR, CD214RR, CD219RR, BRS244RR, and AntaRR). On the other hand, a high differentiation level was evident among the nine $\mathrm{CD}\left(F_{\mathrm{ST}}=0.3630\right)$ and among the six BR $\left(F_{\mathrm{ST}}=0.4517\right)$ cultivars. These results are typical of the genetic structure of self-pollinated species, where most genetic variation is observed among populations.
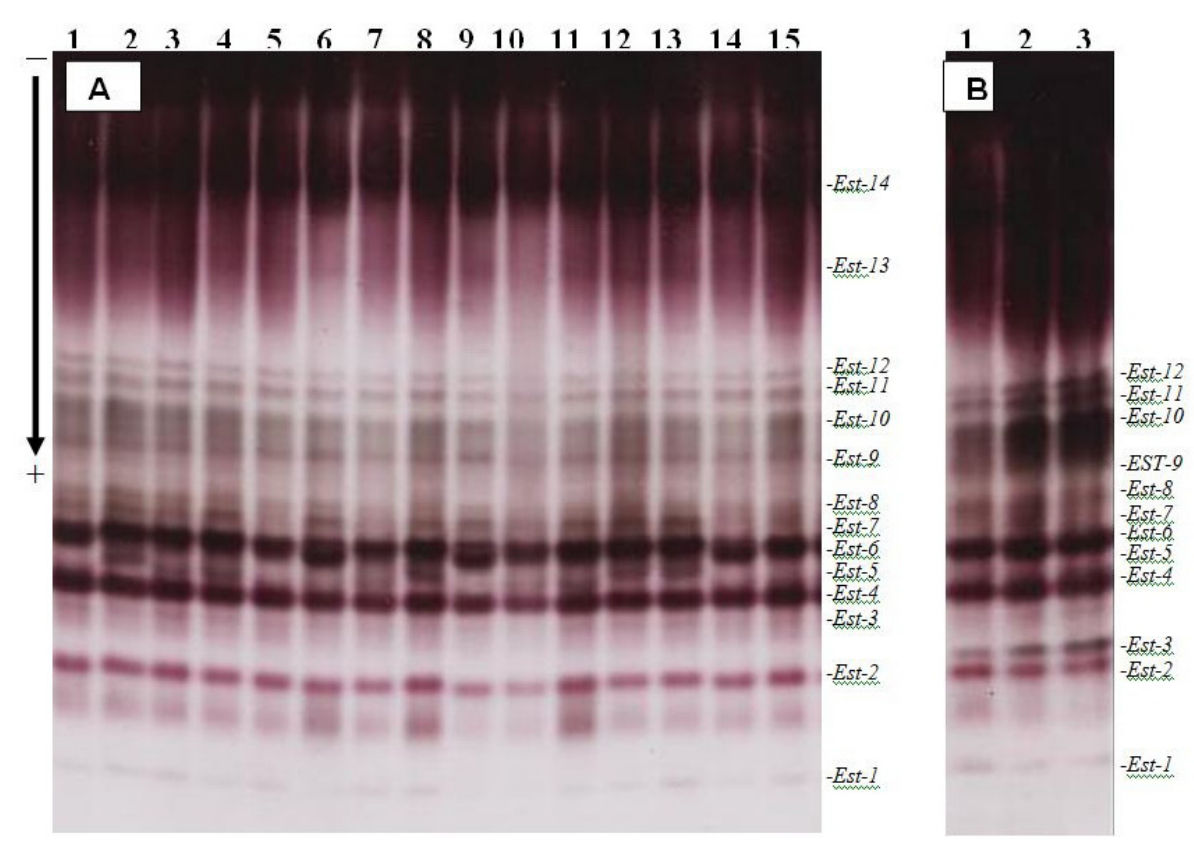

Figure 1. Isozymes $\alpha$ - and $\beta$-esterases of soybean leaves in a polyacrylamide gel electrophoresis system showing the alleles Est-1 $1^{1}$ (lanes 6-11; gel A) and Est-1 $1^{2}$ (lanes 1-5 and 12-15, gel A; lanes 1-3, gel B), Est-21 (lanes 6, 9, 10, and 14, gel A) and Est-2 (lanes 1-5, 7, 8, 11-13, and 15, gel A; lanes 1-3, gel B), Est-31 (lanes 1-3, gel B) and Est-32 (lanes 1-15, gel A; lane 3, gel B), Est-51 (lanes 1, 3-5, 7, 10, 11, 15, gel A; lanes 1-3, gel B), Est-52 (lanes 2, 8, 12, 13, gel A) and Est-5 (lanes 1, 6, 9, 14), Est-6 (lanes 1, 6, 9, 14, gel A) and Est-6 ${ }^{2}$ (lanes 2-5, 7, 8, 10-13, 15, gel A; lanes 1-3, gel B), and the genotype Est-14 1/2 (lanes 1-15, gel A) in the BR37 (gel A) and BRS230 (gel B) cultivars. 
Table 1. Number of polymorphic loci $\left(N_{\mathrm{PL}}\right)$, proportion of polymorphic loci $(\% \mathrm{P})$, number of alleles $\left(N_{\mathrm{A}}\right)$, proportion of alleles per locus $\left(N_{\mathrm{API}}\right)$, effective number of alleles $\left(N_{\mathrm{E}}\right)$, mean observed $\left(H_{\mathrm{O}}\right)$ and expected $\left(H_{\mathrm{E}}\right)$ heterozygosity, and $F_{\text {IS }}$ values in plants of 21 soybean cultivars.

\begin{tabular}{|c|c|c|c|c|c|c|c|c|}
\hline Cultivar & $N_{\mathrm{PL}}$ & $\% \mathrm{P}$ & $N_{\mathrm{A}}$ & $N_{\mathrm{A} / \mathrm{PL}}$ & $N_{\mathrm{E}}$ & $H_{\mathrm{O}}$ & $H_{\mathrm{E}}$ & $F_{\text {IS }}$ \\
\hline CD201 & 2 & 14.28 & 8 & 1.60 & 1.35 & 0.080 & 0.187 & 0.5238 \\
\hline CD202 & 2 & 14.286 & 8 & 1.60 & 1.56 & 0.020 & 0.227 & 0.8959 \\
\hline CD204 & 3 & 21.42 & 8 & 1.60 & 1.55 & 0.140 & 0.289 & 0.4871 \\
\hline CD205 & 2 & 14.28 & 7 & 1.40 & 1.26 & 0.080 & 0.150 & 0.3107 \\
\hline CD206 & 2 & 14.28 & 7 & 1.40 & 1.12 & 0.110 & 0.088 & -0.1715 \\
\hline CD208 & 2 & 14.28 & 7 & 1.40 & 1.30 & 0.020 & 0.171 & 0.8666 \\
\hline CD209 & 3 & 21.42 & 8 & 1.60 & 1.29 & 0.130 & 0.1958 & 0.3084 \\
\hline CD215 & 2 & 14.28 & 7 & 1.40 & 1.21 & 0.000 & 0.1390 & 1.0000 \\
\hline CD216 & 2 & 14.28 & 7 & 1.40 & 1.32 & 0.200 & 0.1750 & 0.0000 \\
\hline BR37 & 4 & 28.57 & 9 & 1.80 & 1.52 & 0.270 & 0.2908 & 0.5858 \\
\hline BR48 & 4 & 28.57 & 9 & 1.80 & 1.26 & 0.150 & 0.1337 & 0.2798 \\
\hline BRS133 & 1 & 7.14 & 6 & 1.20 & 1.08 & 0.070 & 0.0578 & -0.2121 \\
\hline BRS137 & 4 & 28.57 & 10 & 2.00 & 1.57 & 0.190 & 0.2808 & 0.3222 \\
\hline BRS184 & 3 & 21.42 & 9 & 1.80 & 1.36 & 0.020 & 0.1950 & 0.6491 \\
\hline BRS230 & 3 & 21.42 & 8 & 1.60 & 1.15 & 0.060 & 0.1210 & 0.6078 \\
\hline CD212RR & 3 & 21.42 & 8 & 1.60 & 1.50 & 0.220 & 0.2705 & 0.2498 \\
\hline CD213RR & 4 & 28.57 & 9 & 1.80 & 1.43 & 0.140 & 0.2645 & 0.3917 \\
\hline CD214RR & 2 & 14.28 & 8 & 1.60 & 1.23 & 0.000 & 0.1330 & 1.000 \\
\hline CD219RR & 2 & 14.28 & 8 & 1.60 & 1.38 & 0.000 & 0.1480 & 1.000 \\
\hline BR244RR & 4 & 28.57 & 9 & 1.80 & 1.33 & 0.090 & 0.2187 & 0.3970 \\
\hline AntaRR & 2 & 14.28 & 7 & 1.40 & 1.24 & 0.090 & 0.1448 & 0.2517 \\
\hline Total & 5 & 35.71 & 12 & 2.40 & 1.68 & 0.0995 & 0.3061 & 0.3571 \\
\hline
\end{tabular}

Table 2. Fixation coefficients $F\left(F_{\mathrm{IS}}, F_{\mathrm{IT}}, F_{\mathrm{ST}}\right.$; Wright, 1965) and gene flux value $\left(N_{\mathrm{m}}\right)$ in soybean cultivars.

\begin{tabular}{lcccc}
\hline Locus & $F_{\text {IS }}$ & $F_{\text {IT }}$ & $F_{\text {ST }}$ & $N_{\mathrm{m}}$ \\
\hline Est -1 & 0.0041 & 0.1704 & 0.1669 & 1.2473 \\
Est -2 & -0.1087 & -0.0157 & 0.0839 & 2.7298 \\
Est -3 & 0.9514 & 0.9709 & 0.4028 & 0.3707 \\
Est -5 & 0.6726 & 0.8302 & 0.4814 & 0.2693 \\
Est -14 & -0.5665 & -0.1781 & 0.2479 & 0.7585 \\
Total & 0.470 & 0.6749 & 0.3865 & 0.3968 \\
\hline
\end{tabular}

Nei's identity (I) values varied between 0.5538 (plants of the BR37 and BRS133 cultivars) and 0.9995 (plants of CD205 and CD208 cultivars). The genetic basis of BR cultivars (0.5538-0.9748) was found to be broader than the genetic basis of CD cultivars $(0.7058$ for CD205 and CD209 and 0.9995 for CD205 and CD208). A higher genetic identity value was also detected between plants of $\mathrm{CD}$ and $\mathrm{CDRR}$ cultivars $(\mathrm{I}=0.9816)$.

\section{DISCUSSION}

Our results confirm that PAGE can be a powerful procedure for analysis of $\alpha$ - and $\beta$-esterase isozymes from leaf tissues of soybean plants. Fourteen loci for isoesterases were simultaneously evident in the same electrophoresis, using only one enzymatic system. Isozyme studies in other soybean genotypes have revealed 13 and 15 loci from analysis of 8 and 9 enzymatic systems, respectively (Griffin and Palmer, 1995; Hirata et al., 1999). The analysis of various different enzymatic systems generally requires higher cost and time investments. PAGE system $\alpha$ - and $\beta$-esterase isozyme analysis can be used for studies to 
detect genetic diversity in soybean cultivars at a relatively low cost. Esterase polymorphism in soybeans has only been reported for the Est-1 locus (Abe and Ohara, 1992; Hirata et al., 1999). The Est-1 locus was used as an additional marker to differentiate the soybean Japanese population from populations of other countries (Hirata et al., 1999).

The $\alpha$ - and $\beta$-esterase isozyme analysis in the PAGE system showed that the proportions of polymorphic loci $(\% \mathrm{P})$ in the $\mathrm{CD}, \mathrm{BR}$, and RR Brazilian cultivars $(35.7 \%)$ is lower than that in the Japanese $(69 \%)$, Korean $(56 \%)$, and Chinese $(75 \%)$ populations, but the number of alleles per locus (2.4) was similar to the values reported for the Japanese (2.31) and slightly higher than the values of the Korean (2.19) and Chinese (2.13) populations tested by Hirata et al. (1999), in an analysis of 16 loci (protein and isozyme loci). The value of $H_{\mathrm{E}}$ in $\mathrm{CD}, \mathrm{BR}$, and RR soybean cultivars $(0.306)$ was also relatively higher than for the Japanese (0.248), Chinese (0.249), and Korean (0.209) populations. These Japanese, Korean, and Chinese populations, analyzed by Hirata et al. (1999) using isozyme loci, are principally accessions of soybean landraces and local varieties.

Soybean cultivars, including the Brazilian cultivars, have been characterized mainly by DNA markers (Abdelnoor et al., 1995; Priolli et al., 2002, 2004; Bonato et al., 2006; Yamanaka et al., 2007; Fu et al., 2007; Hwang et al., 2008). The microsatellite markers or SSR (simple sequence repeat) loci have been used as tool for cultivar identification, pedigree analysis and the evaluation of genetic distance among Brazilian cultivars (Priolli et al., 2002, 2004; Yamanaka et al., 2007). The number of alleles per locus and proportion of polymorphic loci have been reported from SSR loci analysis, but the observed and expected heterozygosity in SSR loci have not been reported for Brazilian cultivars.

The $\alpha$ - and $\beta$-esterase polymorphisms in the PAGE system in our study had high and low values for observed and expected proportions of heterozygous loci in the 21 different soybean cultivars, indicating that $\mathrm{CD}, \mathrm{RB}$, and RR cultivars are genetically structured. A larger number of heterozygous plants in CD202 $\left(H_{\mathrm{E}}=0.227\right), \mathrm{CD} 204\left(H_{\mathrm{E}}=0.289\right), \mathrm{CD} 216\left(H_{\mathrm{O}}=\right.$ $0.20), \operatorname{BR} 37\left(H_{\mathrm{O}}=0.27\right.$ and $\left.H_{\mathrm{E}}=0.29\right), \operatorname{BRS} 137\left(H_{\mathrm{E}}=0.2808\right), \mathrm{CD} 212 \mathrm{RR}\left(H_{\mathrm{O}}=0.22\right.$ and $\left.H_{\mathrm{E}}=0.2705\right)$, and CD213RR $\left(H_{\mathrm{E}}=0.2645\right)$ cultivars may be a result of different reactions to the environment, preventing uniform plant responses. High heterozygosity indicates that the plant population probably has substantial adaptive genetic variation to overcome environmental changes (Allendorf and Luikart, 2007). Alternatively, reduced heterozygosity reduces the fitness of individuals at loci in which the heterozygous individuals have a relative advantage over homozygous specimens.

Differences in allele frequencies and proportions of heterozygous loci in different populations demonstrated genetic divergence among the 21 cultivars $\left(F_{\mathrm{ST}}=0.3865\right)$. According to Wright (1978), $F_{\mathrm{ST}}$ values between 0.15 and 0.25 indicate high interpopulational divergence levels, or high genetic differentiation level between populations. Limited spatial dispersal and populations frequently disturbed by human interference may cause the high level of differentiation in soybean cultivars. Self-pollination as a primary form of reproduction in soybeans may explain the high degree of genetic structure in the populations. Additionally, high selection pressure adopted in conventional cultivar management may cause the selection of particular genotypes and may create increased spatial heterogeneity. High differentiation levels was evident among the nine $\mathrm{CD}$ and six BR $\left(F_{\mathrm{ST}}=0.4517\right)$ cultivars. Analysis of genetic diversity of 184 soybean cultivars from six different Brazilian breeding programs using 12 microsatellite loci also showed that most of the variance occurred among cultivars within 
breeding programs, and only $5.3 \%$ of the whole variance was due to differences between breeding programs (Priolli et al., 2004). In our study, only $1.7 \%$ of the total variance was due to differences between the COODETEC (CD cultivars) and EMBRAPA (BR cultivars) breeding program cultivars.

The $\alpha$ - and $\beta$-esterase polymorphism in the soybean cultivars also showed low genetic differentiation between $\mathrm{CD}$ and CDRR cultivars $\left(F_{\mathrm{ST}}=0.0261\right)$, indicating that gene insertion and in vitro tissue culture to obtain genetically modified plants have not produced highly differentiated plants. Plants regenerated from tissue culture are frequently genetically altered; somaclonal variation has been included to produce plants with new traits that are genetically stable and inherited in a Mendelian manner as either dominant or recessive traits (Larkin and Scowcroft, 1981). Tissue cultures prepared from roots of individual soybean plants developed RFLP allelic differences at various loci (Roth et al., 1989). However, new alleles for $\alpha$ - and $\beta$ esterase isozymes in RR cultivars were not detected, and other possible mutations induced by in vitro system culture were not sufficient to produce genetic differentiation among originalconventional $(\mathrm{CD})$ and RR cultivars.

Allele frequency analysis in CD, BR, and RR cultivars showed that the Est-1 $1^{1}, E s t-2^{l}$, and Est-14 $4^{2}$ alleles were the most frequent alleles at Est-1, Est-2, and Est-14 loci in all soybean cultivars. Although the physiological role and specific substrate for $\alpha$ - and $\beta$-esterase isozymes in vivo are unknown for soybean, it is possible that the selection processes used by breeding programs to develop important agronomic characteristics have also selected the most frequent alleles at Est-1, Est-2, and Est-14 loci.

Esterase analysis in our study showed high and low genetic diversity within $\mathrm{CD}$ and RB cultivars and high genetic diversity among the 21 soybean cultivars. Understanding the genetic structure of these populations is important and may provide specific and differential culture strategies for each cultivar, depending on whether they have high or low heterozygosity. $\alpha$ - and $\beta$-esterase loci are functional-coding regions of the soybean genome and their analysis in the PAGE system is a conventional, relatively simple procedure that can be used to quickly determine the genetic structure of soybean cultivars.

\section{ACKNOWLEDGMENTS}

The authors thank CAPES (Coordenação de Aperfeiçoamento de Pessoal de Nível Superior, Brasília, DF, Brazil) for financial support.

\section{REFERENCES}

Abdelnoor RV, Debarros EG and Moreira MA (1995). Determination of genetic diversity within Brazilian soybean germplasm using random amplified polymorphic DNA techniques and comparative-analysis with pedigree data. Rev. Bras. Genet. 18: 265-273.

Abe J and Ohara M (1992). New eletrophoretic mobility variations observed in wild soybean (G. soja) distributed in Japan and Korea. Soybean Genet. News 9: 63-72.

Allendorf FW and Luikart G (2007). Conservation and the Genetics of Populations. Blackwell Publishing, Malden, Massachusetts.

Bonato ALV, Calvo ES, Arias CAA, Toledo JFF, et al. (2006). Prediction of genetic variability through AFLP-based measure of genetic distance in soybean. Crop Breed. Appl. Biotechnol. 6: 30-39.

Carvalho VM, Marques RM, Lapenta AS and Machado MFPS (2003). Functional classification of esterases from leaves of Aspidosperma polyneuron M. Arg. (Apocynaceae). Genet. Mol. Biol. 26: 195-198. 
Ceron CR, Santos JR and Campos Bicudo HEM (1992). The use of gelatin to dry cellophane wound slab gels in an embroidering hoop. Braz. J. Genet. 15: 201-203.

Frigo MJ, Mangolin CA, Oliveira RS Jr and Machado MFPS (2009). Esterase polymorphism for analysis of genetic diversity and structure of wild poinsettia (Euphorbia heterophylla) populations. Weed Sci. 57: 54-60.

Fu Y-B, Peterson GW and Morrison MJ (2007). Genetic diversity of canadian soybean cultivars and exotic germplasm revealed by simple sequence repeat markers. Crop Sci. 47: 1947-1954.

Gorman MB (1984). An electrophoretic analysis of the genetic variation in the wild and cultivated soybean germplasm. Diss. Abstr. Int. B. 44: 11.

Griffin JD and Palmer G (1995). Variability of thirteen isozyme loci in the USDA soybean germplasm collections. Crop Sci. 35: 897-904.

Hirata T, Abe J and Shimamoto Y (1999). Genetic structure of the Japanese soybean population. Genet. Res. Crop Evol. 46: 441-453.

Hwang T-Y, Nakamoto Y, Kono I, Enoki H, et al. (2008). Genetic diversity of cultivated and wild soybean including Japanese elite cultivars as revealed by length polymorphism of SSR markers. Breed. Sci. 58: 315-323.

Larkin PJ and Scowcroft WR (1981). Somaclonal variation: a novel source of variability from cell cultures for plant improvement. Theor. Appl. Genet. 60: 197-214.

Li Y, Guan R, Liu Z, Ma Y, et al. (2008). Genetic structure and diversity of cultivated soybean (Glycine max (L.) Merr.) landraces in China. Theor. Appl. Genet. 117: 857-871.

Li Z and Nelson RL (2001). Genetic diversity among soybean accessions from three countries measured by RAPDs. Crop Sci. Soc. Am. 41: 1337-1347.

Miranda ZFS, Arias CAA, Prete CEC, Kiihl RAS, et al. (2007). Genetic characterization of ninety elite soybean cultivars using coefficient of parentage. Pesq. Agropec. Bras. 42: 363-369.

Nei M (1978). Estimation of average heterozygosiy and genetic distance from a small number of individuals. Genetics 89: 583-590.

Oakeshott JG, van Papenrecht EA, Boyce TM, Healy MJ, et al. (1993). Evolutionary genetics of Drosophila esterases. Genetica 90: 239-268.

Orasmo GR, Oliveira-Collet SA, Lapenta AS and de Fatima PSM (2007). Biochemical and genetic polymorphisms for carboxylesterase and acetylesterase in grape clones of Vitis vinifera L. (Vitaceae) cultivars. Biochem. Genet. 45: 663-670.

Pereira AJ, Lapenta AS, Vidigal-Filho PS and Machado MF (2001). Differential esterase expression in leaves of Manihot esculenta Crantz infected with Xanthomonas axonopodis pv. manihotis. Biochem. Genet. 39: 289-296.

Perry MC, McIntosh MS and Stoner AK (1991). Geographical patterns of variation in the USDA soybean germplasm collection: II. Allozyme frequencies. Crop Sci. 31: 1356-1360.

Priolli RHG, Mendes-Junior CT, Arantes NE and Contel EPB (2002). Characterization of Brazilian soybean cultivars using microsatellite markers. Genet. Mol. Biol. 25: 185-193.

Priolli RHG, Mendes-Junior CT, Sousa SMB, Sousa NEA, et al. (2004). Diversidade genética da soja entre períodos e entre programas de melhoramento no Brasil. Pesq. Agropec. Bras. 39: 967-975.

Robin C, Russell RJ, Medveczky KM and Oakeshott JG (1996). Duplication and divergence of the genes of the alphaesterase cluster of Drosophila melanogaster. J. Mol. Evol. 43: 241-252.

Roth EJ, Frazier BL, Apuya NR and Lark KG (1989). Genetic variation in an inbred plant: variation in tissue cultures of soybean (Glycine max (L.) Merrill). Genetics 121: 359-368.

Schwartz DE (1967). E1 esterase isozymes in maize: on the nature of the gene-controlled variation. Proc. Natl. Acad. Sci. U.S. A. 58: 568-575.

Ude GN, Kenworthy JMC, Cregan PB and Alvernaz J (2003). Genetic diversity of soybean cultivars from China, Japan, North America, and North American ancestral lines determined by amplified fragment length polymorphism. Crop Sci. 43: 1858-1867.

Wang LX, Guan RX, Li YH, Lin FY, et al. (2008). Genetic diversity of Chinese spring soybean germplasm revealed by SSR markers. Plant Breed. 127: 56-61.

Wright S (1965). The interpretation of population structure by F-statistics with special regard to systems of mating. Evolution 19: 395-399.

Wright S (1978). Variability Within and Among Populations. In: Evolution and the Genetics of Populations (Wright S, ed.). University of Chicago Press, Chicago, 580.

Xu DH and Gai JY (2003). Genetic diversity of wild and cultivated soybeans growing in China revealed by RAPD analysis. Plant Breed. 122: 503-506.

Yamanaka N, Sato H, Yang Z, Xu DH, et al. (2007). Genetic relationship between Chinese, Japanese, and Brazilian 
soybean gene pools revealed by simple sequence repeats (SSR) markers. Genet. Mol. Biol. 30: 85-88.

Yeh FC, Yang R and Boyle T (1999). POPGENE Version 1.31: Microsoft Window Based Freeware for Population Genetic Analysis: Quick User Guide. University of Alberta, Centre for International Forestry Research, Alberta.

Yoon MS, Lee J, Kim CY, Kang JH, et al. (2009). DNA profiling and genetic diversity of Korean soybean (Glycine max (L.) Merrill) landraces by SSR markers. Euphytica 165: 69-77.

Yu HG and Kiang YT (1993). Genetic variation in South Korean natural populations of wild soybean (Glycine soja). Euphytica 68: 213-221.

Zhou X, Carter Jr TE, Cui Z, Miyazaki S, et al. (2000). Genetic base Japanese soybean cultivars released during 1950 to 1988. Crop Sci. 40: 1794-1802. 